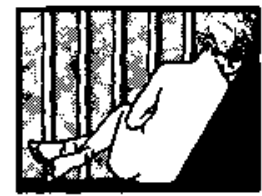

O psicólogo Juarez Alves faz uma descricäo de todas as atividades desenvolvidas na Casa, destacando em particular a importância das Assembléas como uma das formas abertas de organização e de participação de cada um e do conjunto da comunidade:

"O horário para o menino ir à Casa é o da manhã. Se ele não consegue ir pela manhã, perde a chance de estar naCasa naquele dia, já que à tarde ele não é recebido. Ao ser recepcionado, estão à sua disposição um chuveiro com água quente, toalha, bucha, sabonete e roupa para uso interno. $\mathrm{Em}$ seguida, ele toma um lanche, na presença dos educadores. Há, então, uma conversa sobre aquele espaço ou as coisas que aconteceram com ele, recentemente. Inicia-se aí a atividade mais significativa da Casa, no desenvolvimento do Projeto, a Assembléia, que apresentava no início pouca organização. Nesse período ínicial, os meninos se retiravam da Casa no momento em que desejassem.

\section{Os primeiros contatos}

Essas reuniões possibilitaram ao menino revelar, na sua quase totalidade, duas demandas básicas: queriam um lugar para dormir e uma escola para estudar. Isso confirmava dois princípios do projeto: sem albergue e sem alfabetização seria impossível a construção de um projeto de vida junto aos meninos e para eles. Sentimos então que, já passados trinta dias de conhecimento da Casa, era preciso avançar nas etapas do projeto elaborado.

Em primeiro lugar, constatamos a existência de dois grupos na Casa: o dos educadores e o dos meninos que tinham uma presença mais constante e significativa. A interação entre esses dois grupos só foi identificada através da prática, não constando de forma explícita no projeto como ponto fundamental das relaçōes a serem estabelecidas. Se tínhamos o propósito de promover uma nova organização in. terna e externa nas relações com os meninos, era preciso sistematizar ações dentro de uma pedagogia com-

\title{
Vivendo um dia inteiro na Casa
}

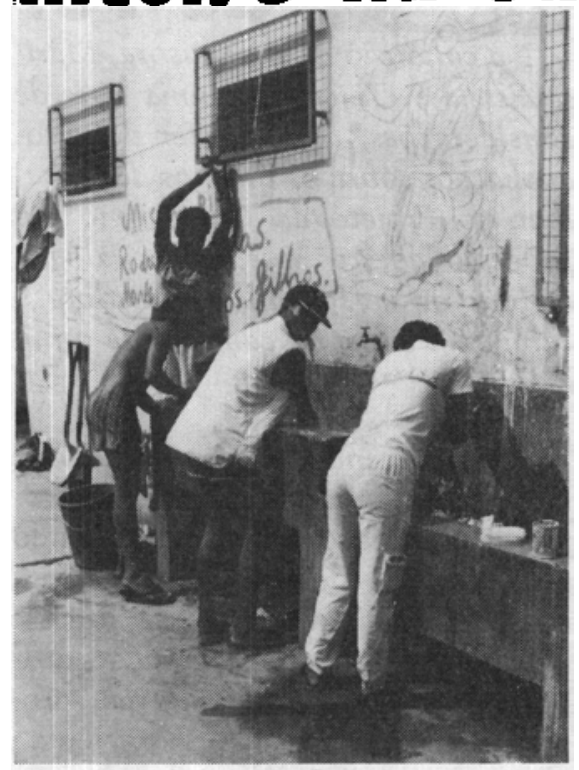

Como atividade de rotina, os meninos cuidam dos objetos pessoais.

promissada e libertadora, em que os espaços da opressão deixassem de existir e o lugar do diálogo fosse construído. É nesse momento que a Assembléia atinge seu caráter sistematizador da socializaçāo buscada a partir da elaboraçāo do projeto. E na Assembléia que fica definido o horário de chegada na Casa - até as nove horas. De oito às nove e trinta, os meninos tomam banho, lavam suas roupas, fazem lanches, enfim, entram em atividades bem pessoais e de forma individual.

\section{Uma rotlna diversificada}

Após as nove e trinta, dois grupos de meninos vão para a alfabetização, um grupo para a musicoterapia, outro grupo para a capoeira e, após uma hora, os grupos se alternam nas atividades desenvolvidas. É bom frisar que o grupo fixo de meninos a serem atendidos diretamente na Casa é de 24, e que seriam distribuídos seis deles para cada atividade. Esse número é apenas referencial, não havendo rigidez na sua composição.

Às onze e trinta, acontece o almoço, ficando livres até às treze e trinta. Nesse momento, todos entram em atividades de caráter formativo, orientadas para o mundo do trabalho, seja atividade de limpeza e de conservaçāo da Casa, seja trabalho em couro ou em madeira. Especificamente, o tra- balho em couro, madeira e chupechupe tem o caráter de geração de renda, estando estas atividades bem aquém do real desejado.

A geração de renda visa a alcançar dois objetivos dos mais significativos: um, o de possibilitar um ganho financeiro para suprir necessidades pessoais, tais como a de ir a um cinema, de poder pagar passagem de ônibus para passeios de fim de semana, tirar documentos, e outros, mas jamais pretende a obtenção de uma renda que venha a suprir todas as necessidades do menino. $O$ segundo objetivo é o de facilitar a elaboração de novas formas de ganhar dinheiro, (além do roubo, tão comum no cotidiano dos bandos). Ageração de renda tem sido um desafio no sentido de encontrar atividades que garantam rentabilidade com custos baixos e que permitam o desenvolvimento e o conhecimento emocional do menino.

As dezesseis horas, fazem um lanche e às dezesseis e trinta são liberados para o pernoite (albergue).

Nessas atividades diárias, temos na sexta-feira às onze horas o horário de lavar roupa da Casa. Os meninos receberam roupas para uso durante as atividades, tendo o compromisso de conservá-las, já que elas têm um período de duração e somente após esse tempo é que recebem novas peças.

Por que fazer Assembléla?

Temos, também, reconhecida como a linha mestra das relações na Casa uma Assembléia na segundafeira às nove e trinta, quando as leis da Casa são formuladas, todas as propostas são discutidas, inclusive a admissão de novos elementos e os compromissos de cada um acertados.

A Assembléia é o momento em que todos - o grupo de meninos e o de educadores - se agrupam para uma discussāo em comum. Aparecem, então, as dificuldades afetivas, a negação aos compromissos duradouros, 0 desejo de estar na Casa e o não saber como preservá-la etc. E nesse estar junto especial que surgem os temas que orientam os conteúdos a serem trabalhados. E aí que o menino reflete e descobre que ele não tem uma consPSICOLOGIA, CIÉNCIA E PROFISSĀO 17 
ciência de si mesmo e que tudo aquilo que revela como sua identidade nada mais é senão os conceitos rotuladores que lhe indicam um lugar na marginalização social, sustentada pelo sistema ideológico em que vivemos. Os meninos se acham incapazes não porque o sejam, mas porque pessoas pertencentes a classes diferentes afirmam que, em sua totalidade, eles são incapazes, marginais.

\section{Um momento malor dos meninos}

E na Assembléia que eles revelam o seu corpo - com suas feridas, queimaduras, roupas esfarrapadas, sua cor negra (em sua maioria) - como o único mensageiro, para a sociedade, daquilo que lhe fizeram. Em compensação, essa sociedade tem a seu favor - contra esses meninos - os meios de comunicação de massa, as diversas instituições, os políticos, os policiais, os empresários e, enfim, as pessoas de sua própria classe social.

Lado a lado, num círculo inacabado, a Assembléia concretamente nos diz do lugar que os meninos ocupam numa sociedade em que a Justiça e o Direito são relativos aos interesses de uma minoria que detém a maioria dos instrumentos convencionais de dominação.

É na Assembléia, momento maior da fala dos meninos, que descobrimos alguns conceitos básicos que podem orientar a atuação da sociedade como um todo na relação com esses meninos.

A Assembléia também nos fala de um espaço em que se constrói outro tipo de relacionamento. Ela nos aparece, de alguma forma, como um lugar da contra-instituição, da contraordem, no sentido de ser a possibilidade de instaurar uma nova maneira de organização; uma outra possibilidade de se pensar e de poder falar de si. Dessa maneira, é o espaço em que se discutem a convivência, as normas, enfim, tudo o que nos torna uma comunidade.

$\mathrm{Na}$ Assembléia, nós, educadores, vivenciamos a angústia do enfrentamento com diferentes instâncias institucionais que inviabilizam, permanentemente, a materialização de propostas de um trabalho que possibilite um novo lugar para esses meninos".

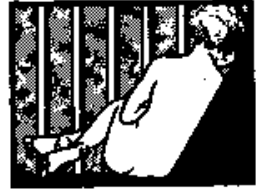

Na condição de supervisora, Marisa Estela S. Tejera tece uma série de considerações, com caráter de autoavaliação, sobre os dilemas de trabaIhar no Projeto da Casa como um processo aberto que, por analogia, lembra os versos do poeta sobre o caminhante que faz caminho ao caminhar:

"Acontecendo é a sensação que nos percorre quando falamos no Projeto. Ele está acontecendo, está sendo possível, está delineando-se, enfim, nós o estamos vivendo ainda. É nesse sentido que não temos definições acabadas, teorizações definitivas, propostas estruturadas. A experiência nos aparece como uma vivência intensa, sempre nova, sempre imprevisível, que nos diz da irrupção. Os meninos são surpreendentes, no sentido amplo da palavra, do que 'sur-preende', do que nos aprisiona e, ao mesmo tempo, mantém esse caráter constante de surpresa.

Muitas coisas têm sido reformuladas no Projeto, muito se repensou e se discutiu. O projeto inicial não é o mesmo, por diversas razōes como, por exemplo, a dificuldade com as leis, com os horários, enfim, com tudo aquilo que pretendia guardar uma certa organização.

\section{Avaliando algumas atividades}

A musicoterapia não foi bem aceita pelo grupo. Nossa colega Ivana Maria F. Vieira nos diz que é preciso trabalhar de uma forma menos direcionada. São os meninos que demandam essa abordagem. Assim é possível integrá-los com o trabalho, com a proposta, criar um movimento. A musicoterapia se integra nas outras atividades e no cotidiano da Casa.

A mesma coisa aconteceu com a arte-terapia: de um momento de enrijecimento inicial à possibilidade de elaborar painéis, cenários, peças de teatro, enfim, são muitos os exemplos que teríamos para relatar e as discussões que poderíamos levantar. Queremos, porém, deixar claro que essa idéia de movimento é o que se impõe.
A Casa da Rua Ubá não é um lugar de permanência, não é um lugar de chegada. A trajetória dos meninos não acaba ali e, pelo menos, não é essa a nossa pretensão. Ela é, essencialmente, um lugar de trânsito, de passagem, de abertura para outros espaços.

Muitas determinantes têm atravessado nosso trabalho: a dificuldade de concretizar uma forma de geração de renda, as ambigüidades das respostas institucionais etc.

Podemos perguntar-nos o que torna possível concretizar um projeto. Aqui nos referimos, em primeiro lugar, à Febem. Somos uma equipe que, de uma forma provisória ou não, está vinculada a uma Instituição, mas nenhuma instituição é inteira. Ela tem porosidades, suas aberturas, que a tornam incentivadora e sabotadora ao mesmo tempo.

A análise institucional tem-nos ensinado que o mesmo lugar que possibilita é o que paralisa. Temos vivido isso muito claramente. Foram constantes, por exemplo, os enfrentamentos, os desentendimentos, os malentendidos entre a Casa da Rua Ubá c - CERT (Centro de Triagem da FEBEM).Podemos pensar que tudo é FEBEM, mas isso não é tão claro assim. O movimento das instituiçōes não é linear, não é único, mas contraditório, seguindo caminhos que nos dizem do possível e impossível, ao mesmo tempo.

Sentimos a pressão da sociedade, do que está 'fora'. Nos passeios, as pessoas olhavam o grupo de uma forma desconfiada e receosa. Nas negativas dos proprietários quando se tentava alugar uma casa: se é para meninos de rua, não se aluga - era o que nos diziam.

É possivel que tudo isso tenha contribuído para tornar-nos uma mini-comunidade que se autodefende, que se coloca contra algo, que pensa, ilusoriamente, que $o$ inimigo está fora. Esta é uma das tantas questões que ficam para ser pensadas com mais rigor por parte de nosso grupo de técnicos. 